\section{Phase Variation}

$\mathrm{T}$ HE family Acridiidæe includes the so-called 'short-horned' grasshoppers and locusts. Locusts are, in fact, grasshoppers showing special behaviour : they differ from other members of their family on account of their habit, under suitable ecological conditions, of becoming predominantly gregarious, and migrating considerable distances in large swarms.

In 1921, B. P. Uvarov formulated the theory that locusts occur in two forms or phases, hitherto regarded as separate species. In one phase, namely, solitaria, these insects do not differ in behaviour from other short-horned grasshoppers. In the other phase-gregaria - they become gregarious and swarm. In this phase their nymphal coloration is very different from that of the solitary phase and when they become adult, difference in form and the proportional growth of parts reveal themselves. Uvarov's theory was confirmed experimentally by Faure in 1932 and later by others. It has been generally believed that the existence of such phases is a peculiarity of locusts alone. Quite recently, however, I. A. Rubtzov* has shown that an essentially similar phenomenon also occurs in non-swarming short-horned grasshoppers, but that the amplitude of such phase differences is less pronounced than in locusts. Rubtzov's observations were carried out in Siberia and embodied in a paper written in the Russian language. Biologists are indebted to Uvarov for translating this paper and assisting in its publication.

Rubtzov was impressed by the colour variations found in a number of species of grasshoppers. They were found to differ in coloration more or less in accordance with the population density per unit area of territory. Individuals collected from relatively dense associations, with up to 300 grasshoppers per square metre, were notably dark-coloured, larger and had longer wings than those distributed in the proportion of one, or fewer, over the same unit area. These differences are especially marked in Aeropus sibiricus and Chorthippus albomarginatus, while a number of other species can be arranged in descending

*Rubtzov, "Phase Variation in Non-Swarming Grasshoppers", Bull. Entomol. Res., 26, Pt. 4, 499-520 (Dec. 1935).

\section{in Grasshoppers}

order of their tendency to show marked colour differences. The most pronounced differences are found in $A$. sibiricus, which is an active species tending to form dense aggregations of individuals. These differences are almost equally well shown in $C$. albomarginatus. In all cases, the dark-coloured forms occurring collectively are interpreted as representing the phase gregaria, while the pale examples found singly and sparsely are regarded as representing the solitaria phase. This conclusion is supported by such experimental evidence as is available.

Thus, individuals of $C$. albomarginatus, reared in isolation, showed a tendency to develop into the pale-coloured solitaria form, while those reared gregariously, in crowded conditions, produced a very definite gregaria type. Apart from the colour differences alluded to, the supposed phase differences are also betrayed in: (I) solitaria individuals being smaller, with femur and tegmen shorter ; (2) shortening of the tegmen in solitaria being more pronounced than that of the femora, the ratio being greater in solitaria than gregaria; and (3) variability in solitaria being always greater than in gregaria-as can be seen by comparing the maximum and minimum figures. Rubtzov's data are accompanied by coloured figures portraying supposed phase differences and they unmistakably suggest that we have, among non-swarming grasshoppers, clear evidence of the existence of those same phases that feature so markedly in the economy of locusts.

A further phenomenon, discussed by Rubtzov, can only be very briefly alluded to here. He shows that a homologous series of colour variations reveal themselves through many species of Acridiidæ. These are inheritable variations and, according to him, each such race possesses the potentiality, to a greater or lesser degree, to exhibit phase characteristics. The latter, as it were, are super-added to the former in response to the extreme conditions of individual life. In practice, it resolves into the necessity, fully recognised by this author, of clearly determining which race of a given species is being utilised in all studies designed to explore the phase idea.

A. D. Imms.

\title{
Underground Water Supplies
}

$\mathrm{T}$ HE Cantor Lectures of the Royal Society of Arts, delivered last winter by Dr. Bernard Smith, director of the Geological Survey of Great Britain, dealt with the "Geological Aspects of Underground Water Supplies". The lectures, which give a comprehensive review of the geological conditions affecting water supplies from underground sources, are now available. In his first lecture, Dr. Smith alluded to the universality of underground water, though, in some cases, it might lie at depths too great to be of practical value, and stated that most of it, in Great Britain, is rain water, which has made its way down from the surface, though a residual quantity of 'fossil' or 'connate' water may have been held in the rocks for great periods of time. Rainfall disappears from the surface of the ground chiefly by run-off, and secondarily by percolation, evaporation and absorption by vegetation, the relative proportions at any given locality depending upon the topography, the degree of rainfall, the porosity of the soil or rock, the amount of water in the soil at the time, the amount of vegetation and the humidity of the atmosphere.

While run-off constitutes surface waters (rivers, lakes, etc.), it should be recognised that much of what is measured as run-off is actually a steady 
contribution to the streams and rivers by means of springs and seepages from the underground stores built up by percolation, and it was emphasised that in cases during the past drought where reservoirs or lakes utilised for public supply were maintained at a fair level, this was owing entirely to underground water which issued steadily as feeders for the impounded supply. The relative proportions of evaporation, run-off and percolation vary greatly in different localities and seasons, so that general formulæ applicable to any district cannot be used with safety. Evaporation may be $\mathbf{5 0}$ per cent of the rainfall ; run-off up to 92 per cent and percolation 80 per cent or even $90-95$ per cent.

The properties of rocks in regard to absorption and transmission of water were discussed by $\mathrm{Dr}$. Smith, who pointed out the distinction between porosity and perviousness, stating in regard to the former that 30-40 per cent of the volume of a mass of loose sand and gravel is represented by pore-space, whilst that of naturally cemented sands and gravels is only half that amount. On the average, igneous rocks have a pore space of 1 per cent, shale has 4 per cent and limestones have an average of about 5 per cent. On the other hand, the porosity of chalk attains a maximum of about 50 per cent. Pore spaces vary in size from the microscopic (micropores) to those visible to the naked eye (macropores), and the relative proportions of these to the total porosity of a rock determine to a large extent its perviousness (apart from fissures).

The perviousness of a rock is its capacity to allow water to pass through it, and depends not entirely upon the porosity (total volume of pore space), but rather on the size of the pore spaces and their continuity or interconnexion one with another. In most districts, the rocks are saturated below a depth dependent upon several factors-porosity, amount of rainfall and surface profile. In permeable rock, the surface of the saturated zone is termed the 'water table' and the water below it 'ground water'. Above the water table, in the sometimes-called 'zone of aeration', is 'wandering' or 'vadose' water. Water tables are fairly easy to determine in the comparatively unaltered stratified rocks, but not so easy in the impervious, or relatively impervious rocks, exemplified by the more ancient strata and by igneous rocks.
While in granitic areas large supplies are best sought from streams, yet many smaller supplies are to be found underground, due to the water held in the joints. This is particularly the case in Cornwall and Devon. As a class, however, granitic and kindred rocks are not good aquifers, and, in his second lecture, Dr. Smith discussed the Upper Palæozoic, Mesozoic and Tertiary strata, in which underground water occurs in large quantities. The fluctuation of the water table and the breaking out of bournes were described, with instances in the chalk uplands and elsewhere, and reference was made to the researches of Baldwin Latham and others.

Artesian wells and basins received explanatory notice, and it was pointed out that some artesian wells are very deep, having been bored to $4,000 \mathrm{ft}$. in Berlin and in St. Louis and Pittsburgh. These are deeper than any in Great Britain, most of which range at various depths up to $1,000 \mathrm{ft}$., with specially deep cases at Ottershaw (1,585 ft.), Virginia Water $(1,430 \mathrm{ft}$.$) and Boultham, Lincoln (1,562 \mathrm{ft}$.$) . The$ exhaustion of artesian wells may be brought about by over-pumping of the natural reservoir, clogging of the rock pores, unsatisfactory casing and heavy pumping from neighbouring wells. Of the pervious, or partly pervious, formations of Great Britain, the Carboniferous, Millstone Grit and Coal Measures; the Triassic sandstones, the Inferior and Great Oolites, the Lower and Upper. Greensands and the Chalk may be regarded as the chief water-bearing strata.

In the final lecture, the geological complications (faults, flexures, cover) affecting the circulation of underground water were considered, the variation in thickness of strata and missing formations. The best way of studying the question of thickness is to draw 'isopachytes' or 'lines of equal thickness'. This information, together with surface contours related to Ordnance datum, should prove of great utility. Another point of interest to hydro-geologists and water engineers is the change in the quality of water beneath cover, from that of water at the outcrop. Most waters, where traced down an artesian slope, or into an artesian basin, are found to change in mineral character, sometimes quite rapidly.

Dr. Smith concluded his review by remarking that the question of locating supplies is often a complex matter, demanding considerable knowledge from the hydro-geologist and skill from the water engineer.

\section{Recent Developments in Luminous Discharge Tubes}

$I^{N}$ the Electrician of January 31, Mr. C. C. Paterson gives an interesting account of recent developments in luminous discharge tubes. There are two directions in which developments are making rapid progress. The first is the use of 'super pressure' lamps, and the second is the use of luminescent powders.

The high-pressure mercury vapour lamp which runs at a pressure of 150 atmospheres is a very courageous step in advance, but it is not yet known whether it will prove suitable for practical use. In the ordinary mercury vapour lamp, the vapour is under a pressure of two atmospheres; the huminous column does not fill the tube, but contracts into a 'rope' stretched along its axis, and most of the power is being expended inside this. As the vapour pressure increases, the total volume of the luminous vapour diminishes, and as the power is concentrated in this, the ionisation becomes extremely intense and the intrinsic brilliancy greatly increases.

The possibility of the usefulness of luminescent powders has now been demonstrated in the case of cold cathode (high voltage) tubes, and doubtless they will soon be applied to hot cathode tubes. Luminescent powders have been used for some years, but research has now shown methods of greatly enhancing their brilliancy. Mercury vapour has marked radiation in the ultra-violet, and when it falls on a suitable luminescent material its wave-length becomes longer and the radiation becomes visible. Zinc and cadmium sulphides are well known to be luminescent, but there 